\title{
Roles of Infectious Diseases Consultant Pharmacists and Antimicrobial Stewardship Pharmacists: A Survey of Canadian Tertiary Care Academic Hospitals
}

\author{
Jessica E Beach, Tasha D Ramsey, Sean K Gorman, and Tim T Y Lau
}

\begin{abstract}
Background: Infectious diseases consultant (IDC) pharmacists work within an IDC service to care for inpatients with complex infections. With Accreditation Canada's new Required Organizational Practice promoting the establishment of antimicrobial stewardship (AMS) programs, AMS pharmacists are being employed in acute care hospitals. There is potential for overlap in responsibilities between IDC and AMS pharmacists, but there is no literature outlining the current duties for each group in Canada.
\end{abstract}

Objective: To describe the demographic characteristics and roles of IDC and AMS pharmacists in Canadian tertiary care academic hospitals.

Methods: A survey of IDC and AMS pharmacists at Canadian tertiary care academic hospitals was conducted between February and April 2015. The questionnaire included questions about the pharmacist's experience, education, and training; the institution where the pharmacist was practising; the IDC or AMS team characteristics; and the pharmacist's roles in clinical, educational, administrative, and research sectors.

Results: The survey response rate was $77 \%$ (68/88). The 68 respondents self-identified as IDC pharmacists (14 [21\%]), AMS pharmacists (34 [50\%]), or dual-role IDC and AMS pharmacists (20 [29\%]). Compared with AMS pharmacists, IDC pharmacists reported more of the following unique clinical activities: directly communicating with patients, attending rounds, involving patients in decision-making, and providing patient education. The 3 groups of pharmacists described similar educational responsibilities. The AMS pharmacists performed more of the following administrative and research duties: development of antibiograms and preprinted orders, collection of antimicrobial metrics, and drug-use evaluations for antimicrobials. Dual-role IDC and AMS pharmacists were involved in fewer of the unique activities described by those who practised within a single subspecialty.

Conclusions: Self-identified IDC and AMS pharmacists in Canadian tertiary care academic hospitals were performing many similar roles; however, distinct differences within the clinical, administrative, and research domains were identified among IDC pharmacists, AMS pharmacists, and those who identified as dual-role IDC and AMS pharmacists.

Keywords: antimicrobial stewardship, infectious diseases, pharmacy practice, pharmacist, survey

\section{RÉSUMÉ}

Contexte : Les pharmaciens consultants en maladies infectieuses travaillent au sein d'un service de consultants en maladies infectieuses afin de prodiguer des soins aux patients hospitalisés atteints d'infections complexes. Or, en raison de la nouvelle Pratique organisationnelle requise d'Agrément Canada qui encourage la mise en œuvre de programmes de gérance des antimicrobiens, des pharmaciens sont affectés à cette fonction dans les hôpitaux de soins de courte durée. On distingue un possible chevauchement des responsabilités entre les pharmaciens consultants en maladies infectieuses et ceux chargés de la gérance des antimicrobiens, mais il n'y a aucun document qui définit les responsabilités actuelles pour chacun de ces groupes au Canada.

Objectif : Décrire les caractéristiques démographiques et les rôles des pharmaciens consultants en maladies infectieuses et de ceux chargés de la gérance des antimicrobiens dans les hôpitaux universitaires de soins tertiaires au Canada.

Méthodes : Entre février et avril 2015, on a mené un sondage auprès des pharmaciens consultants en maladies infectieuses et de ceux chargés de la gérance des antimicrobiens travaillant dans les hôpitaux universitaires de soins tertiaires au Canada. Les questions portaient, entre autres, sur l'expérience du pharmacien, ses études et sa formation, l'établissement où il travaillait, les caractéristiques des équipes de consultants en maladies infectieuses et de gérance des antimicrobiens ainsi que sur ses rôles dans les secteurs cliniques et administratifs et dans les secteurs de la formation et de la recherche.

Résultats : Le taux de réponse au sondage était de $77 \%$ (68/88). Les 68 répondants s'identifiaient comme des pharmaciens consultants en maladies infectieuses (14 [21\%]), des pharmaciens chargés de la gérance des antimicrobiens (34 [50\%]) ou des pharmaciens occupant les deux rôles (20 [29\%]). Comparativement à leur collègues chargés de la gérance des antimicrobiens, les pharmaciens consultants en maladies infectieuses ont davantage indiqué accomplir les activités cliniques uniques suivantes : communiquer directement avec les patients, participer aux tournées médicales, amener les patients à participer aux prises de décisions et offrir des conseils aux patients. Les trois groupes de pharmaciens ont évoqué des responsabilités éducatives similaires. Les pharmaciens chargés de la gérance des antimicrobiens accomplissaient davantage les tâches administratives et de recherche suivantes : élaboration d'antibiogrammes et d'ordonnances préimprimées, cueillette de mesures sur les antimicrobiens et évaluation de l'utilisation des antimicrobiens. Les pharmaciens 
qui cumulaient les deux rôles participaient à un moins grand nombre des activités uniques décrites par ceux qui exerçaient une seule sous-spécialité.

Conclusions : Les pharmaciens des hôpitaux universitaires de soins tertiaires au Canada qui s'identifiaient eux-mêmes comme des pharmaciens consultants en maladies infectieuses ou des pharmaciens chargés de la gérance des antimicrobiens exécutaient bon nombre de tâches similaires. Cependant, des différences marquées en ce qui touche aux domaines clinique et administratif et à celui de la recherche ont été repérées entre les pharmaciens consultants en maladies infectieuses, ceux chargés de la gérance des antimicrobiens et ceux occupant les deux rôles.

Can J Hosp Pharm. 2017;70(6):415-22

Mots clés : gérance des antimicrobiens, maladies infectieuses, pratique de la pharmacie, pharmacien, sondage

\section{INTRODUCTION}

$\mathrm{P}$ harmacists have an established role in optimizing antimicrobial use in hospitals. ${ }^{1,2}$ Traditionally, pharmacists who specialize in the field of infectious diseases are responsible for ensuring that antimicrobial use in their institutions is safe and effective, as well as providing comprehensive care to inpatients managed by the institutions' infectious diseases consultant (IDC) services. Knox and others ${ }^{2}$ summarized the scope of practice of infectious diseases pharmacists, which includes providing education, monitoring antimicrobial use, conducting audit of and feedback on therapy, developing policies and guidelines, initiating oral antimicrobial therapy, adjusting antimicrobial dosages, monitoring therapeutic drug concentrations, and participating on infection control committees.

Antimicrobial stewardship (AMS) is the practice of ensuring that antimicrobials are used appropriately to improve patient outcomes and to prevent resistance, minimize adverse events, eliminate unnecessary usage, and decrease costs. ${ }^{3}$ Although the concept of AMS was established in the 1970s, only recently has it been recognized as an essential practice in optimizing the quality of antimicrobial use. ${ }^{4,5}$ As of 2013, Accreditation Canada has mandated AMS practice in hospitals by recommending the development of a formalized AMS program as a Required Organizational Practice (ROP). ${ }^{6}$ The ROP handbook states that a successful AMS program requires an interdisciplinary approach, with pharmacists being integral members of the team. ${ }^{6}$

With the emergence of AMS programs, the roles of traditional infectious diseases and general clinical pharmacists are being redefined as new responsibilities are developed for those in AMS positions. ${ }^{3,7}$ However, overlap remains among the responsibilities of infectious diseases pharmacists, AMS pharmacists, and clinical pharmacists. Pharmacists in a multidisciplinary antimicrobial program are key members of the team, and their responsibilities include reviewing patients with complex needs, participating in educational meetings, attending rounds, and streamlining initial empirical antimicrobial treatment once microbiology reports become available. ${ }^{7}$ Similarly, Bartlett and Siola ${ }^{8}$ described the role of clinical pharmacists without infectious diseases training in their community hospital's AMS program, which involved performing parenteral-to-oral antimicrobial conversions, managing dose adjustments, and monitoring culture and sensitivity results. In October 2014, there were 32 employment postings for infectious diseases pharmacists in the United States, and 23 (72\%) of the postings indicated AMS as one of the functions for these positions. $^{9}$

As health systems across Canada continue to promote and support AMS in the institutional setting, the optimal model of pharmacy support for AMS needs to be defined. Moreover, every pharmacy model should achieve AMS-related goals, while balancing other high-value priorities for patients and the health system. ${ }^{10}$

To our knowledge, the roles of Canadian IDC and AMS pharmacists have not been characterized. The aims of this study were to describe the experience, education, and training of IDC and AMS pharmacists in Canadian tertiary care academic hospitals; the characteristics of the institutions, IDC services, and AMS programs in which these pharmacists work; and the pharmacists' clinical, educational, administrative, and research roles.

\section{METHODS}

\section{Study Design and Participants}

This quantitative survey-based study was undertaken to assess the characteristics of IDC and AMS pharmacists. A list of tertiary care academic hospitals was compiled from the membership list of the Association of Canadian Academic Healthcare Organizations (now known as HealthCareCAN) ${ }^{11}$ and a report from the National Task Force on the Future of Canada's Academic Health Sciences Centres. ${ }^{12}$ Potential participants were identified predominantly by contacting the pharmacy department of each tertiary care academic hospital to determine whether the institution employed IDC or AMS pharmacists. Because not all pharmacists working at a given tertiary care centre were employed by the institution's pharmacy department, additional IDC and AMS pharmacists were identified from institution websites and 
through the Canadian Society of Hospital Pharmacists Infectious Diseases Pharmacy Specialty Network (by asking members of the network to contact the authors if they were interested in participating in the study).

Pharmacists employed at any Canadian tertiary care academic hospital who self-identified as working in an IDC or AMS position were included. An IDC pharmacist was defined as a pharmacist acting in a clinical capacity with an inpatient IDC team. An AMS pharmacist was defined as a pharmacist working directly as a core member with a formally funded institutional AMS program. Pharmacists who identified as working in both an IDC and an AMS capacity were classified as dual-role IDC and AMS pharmacists. Pharmacists who had not formally begun their IDC or AMS role (defined as having been in the position for less than 1 day) and those unable to complete the questionnaire in English were excluded.

\section{Development and Dissemination of the Questionnaire}

A questionnaire was developed by adapting the question framework from a previously published survey of critical care pharmacists. ${ }^{13}$ Modifications were made to encompass elements specific to the roles of IDC and AMS pharmacists. A pilot version was evaluated by 5 clinical pharmacy specialists for content and clarity. Following modifications based on their feedback, the final questionnaire, containing 42 questions, was distributed to the IDC and AMS pharmacists identified by the study team. The anonymous questionnaire included questions in the following domains: the pharmacist's experience, education, and training; the institution of practice; information about the IDC or AMS team; and the pharmacist's roles in clinical, educational, administrative, and research sectors. Questions were predominantly closed-ended, including questions with yes/no answers and questions with specified response options (see complete question- naire in Appendix 1, available at www.cjhp-online.ca/index.php/ cjhp/issue/view/124/showToc). A link to the questionnaire was distributed to eligible IDC and AMS pharmacists across Canada over an 8-week period (February 10 to April 7, 2015) by e-mail; the questionnaire itself was available through an internet-based questionnaire platform (SurveyMonkey Inc, Palo Alto, California; www.surveymonkey.com). A reminder e-mail was sent to participants every 2 weeks to encourage participation. Along with the link to the questionnaire, the e-mail to potential participants included a cover letter introducing the investigators, describing the study concept and objective, and outlining the expected involvement of participating pharmacists. Pharmacists who responded to the questionnaire were assumed to have read the cover letter and given their consent to participate in the study. Participation was voluntary, and questionnaire responses were anonymized.

The study was approved by both the University of British Columbia Behavioural Research Ethics Board and the Interior Health Authority Research Ethics Board.

\section{Data Analysis}

The SurveyMonkey web-based questionnaire platform was used to collect, aggregate, and analyze the responses. Descriptive statistics were used to summarize and report data.

\section{RESULTS}

Ninety-three pharmacists were identified during the recruitment phase, and the link to the survey questionnaire was sent to these pharmacists by e-mail. According to their responses to the initial participant screening questions, 5 of these pharmacists were excluded, because they had not formally started their positions or no longer worked at a tertiary care academic hospital, which left 88 eligible pharmacists (Figure 1).

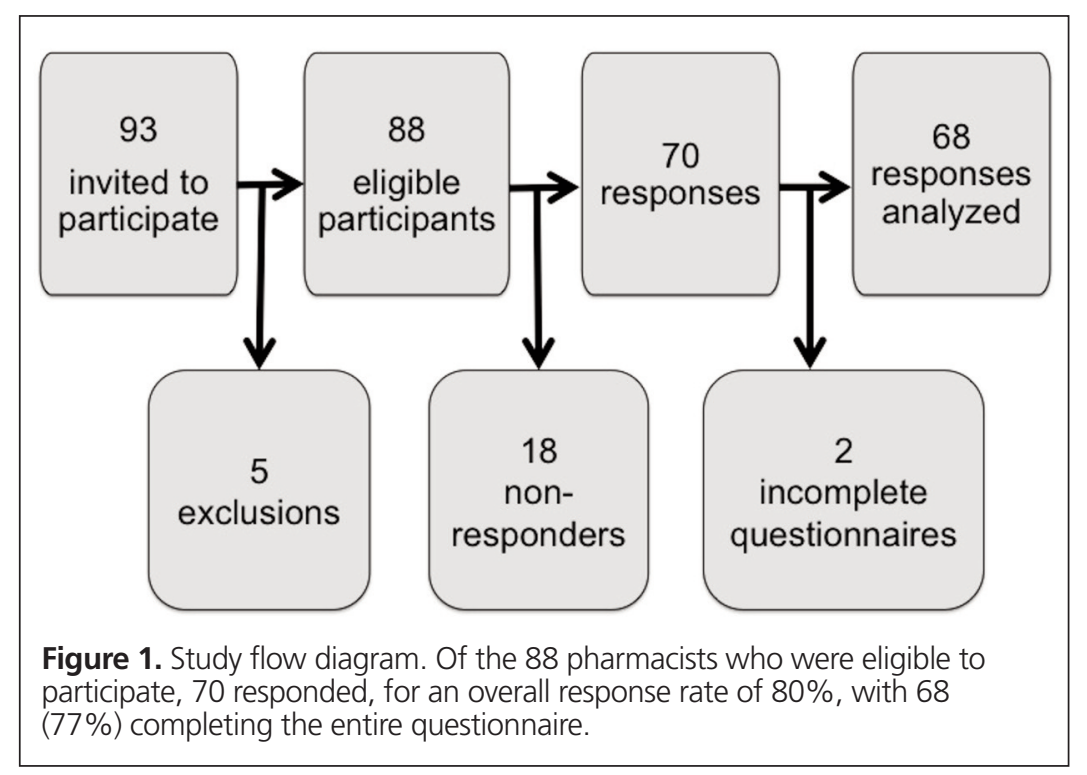


The 88 eligible pharmacists were practising across Canada: $8(9 \%)$ in Alberta, $13(15 \%)$ in British Columbia, 3 (3\%) in Manitoba, 3 (3\%) in New Brunswick, 2 (2\%) in Newfoundland and Labrador, 1 (1\%) in Nova Scotia, 44 (50\%) in Ontario, $12(14 \%)$ in Quebec, and 2 (2\%) in Saskatchewan. Of the 88 eligible participants, 70 provided responses; however, 2 of the returned questionnaires were incomplete (with at least 1 question left unanswered). Therefore, 68 completed questionnaires were analyzed, representing a response rate of $77 \%$ (68/88). Of the 68 respondents, $14(21 \%)$ self-identified as IDC pharmacists, 34 (50\%) as AMS pharmacists, and 20 (29\%) as dual-role IDC and AMS pharmacists. Forty-three pharmacists reported the presence of both IDC and AMS pharmacists at their institutions, and 20 (47\%) of these 43 indicated that different individuals (i.e., more than one person) filled these particular roles.
Pharmacists' hospital experience, education, and training are provided in Table 1 . At least 10 years of hospital pharmacy experience was reported by 9 (64\%) of the 14 IDC pharmacists, 15 (44\%) of the 34 AMS pharmacists, and 14 (70\%) of the 20 dual-role pharmacists. The remaining 30 pharmacists described having less than 10 years of experience. Additional training related to infectious diseases or AMS was reported by $6(43 \%)$ of the 14 IDC pharmacists, 19 (56\%) of the 34 AMS pharmacists, and $12(60 \%)$ of the 20 dual-role pharmacists. Nine $(30 \%)$ of the 30 pharmacists with less than 10 years of experience had additional infectious diseases or AMS training, whereas 28 (74\%) of the 38 pharmacists with 10 or more years of experience had additional training. Pharmacy residency training was indicated by $8(57 \%)$ of the 14 IDC pharmacists, 20 (59\%) of the 34 AMS pharmacists, and 12 (60\%) of the 20 dual-role pharmacists.

Table 1. Experience, Education, and Training of Pharmacists Surveyed

\begin{tabular}{lrrrr} 
& \multicolumn{5}{c}{ Pharmacist Group; No. (\%) of Respondents } \\
\cline { 2 - 5 } Characteristic & IDC $(\boldsymbol{n}=\mathbf{1 4})$ & AMS $(\boldsymbol{n}=\mathbf{3 4})$ & Dual-Role $(\boldsymbol{n}=\mathbf{2 0})$ & Total $(\boldsymbol{n}=\mathbf{6 8})$ \\
\hline Hospital experience & $5(36)$ & $19(56)$ & $6(30)$ & $30(44)$ \\
$<10$ years & $9(64)$ & $15(44)$ & $14(70)$ & $38(56)$ \\
$\geq 10$ years & & & & \\
\hline Education & $8(57)$ & $20(59)$ & $12(60)$ & $40(59)$ \\
Residency & $2(14)$ & $13(3)$ & $2(10)$ & $5(7)$ \\
Fellowship & $8(57)$ & $13(38)$ & $9(45)$ & $30(44)$ \\
Postgraduate PharmD & $2(14)$ & $9(26)$ & $2(10)$ & $13(19)$ \\
Master's & $0(0)$ & $2(6)$ & $0(0)$ & 2 \\
PhD & $6(43)$ & $19(56)$ & $12(60)$ & $37(54)$ \\
\hline Infectious diseases/AMS training & $8(40)$ & $31(46)$ \\
Yes & $8(57)$ & $15(44)$ & $8(40)$ &
\end{tabular}

AMS = antimicrobial stewardship, IDC = infectious diseases consultant.

Table 2. Institutional Characteristics (in Relation to Respondent Groups)

\begin{tabular}{|c|c|c|c|c|}
\hline \multirow[b]{2}{*}{ Institutional Characteristic } & \multicolumn{4}{|c|}{ Pharmacist Group; No. (\%) of Respondents } \\
\hline & IDC $(n=14)$ & AMS $(n=34)$ & Dual-Role $(n=20)$ & Total $(n=68)$ \\
\hline \multicolumn{5}{|l|}{ Bed capacity } \\
\hline $1-100$ & $0 \quad(0)$ & 1 (3) & $0 \quad(0)$ & 1 (1) \\
\hline $101-300$ & $2(14)$ & $5(15)$ & $3(15)$ & $10(15)$ \\
\hline $301-500$ & $4(29)$ & $9(26)$ & $7(35)$ & $20(29)$ \\
\hline$>500$ & $8(57)$ & $19(56)$ & $10(50)$ & $37(54)$ \\
\hline \multicolumn{5}{|l|}{ Patient population* } \\
\hline Adult & $13(93)$ & $28(82)$ & $18(90)$ & $59(87)$ \\
\hline Pediatric & $7(50)$ & $17(50)$ & 7 (35) & $31(46)$ \\
\hline Geriatric & $7(50)$ & $24(71)$ & $8(40)$ & $39(57)$ \\
\hline \multicolumn{5}{|l|}{ No. of pharmacists employed } \\
\hline $1-10$ & 1 (7) & $\begin{array}{ll}0 & (0)\end{array}$ & $1(5)$ & 2 (3) \\
\hline $11-20$ & $0 \quad(0)$ & $8(24)$ & $3(15)$ & $11(16)$ \\
\hline$>20$ & $13(93)$ & $26(76)$ & $16(80)$ & $55(81)$ \\
\hline \multicolumn{5}{|l|}{ Pharmacy residency program } \\
\hline Yes & $14(100)$ & $26(76)$ & $17(85)$ & $57(84)$ \\
\hline No & $0 \quad(0)$ & $8(24)$ & $3(15)$ & $11(16)$ \\
\hline
\end{tabular}


This single copy is for your personal, non-commercial use only.

For permission to reprint multiple copies or to order presentation-ready copies for distribution, contact CHHP at publications@cshp.ca

Table 3. Characteristics of IDC Services and AMS Programs, by Pharmacist Respondent

\begin{tabular}{|c|c|c|c|c|c|c|c|}
\hline \multirow{3}{*}{$\begin{array}{l}\text { Core Member of } \\
\text { Service/Program } \\
\text { IDC service }\end{array}$} & \multicolumn{7}{|c|}{ Pharmacist Group; No. (\%) of Respondents } \\
\hline & \multirow{2}{*}{$\frac{\text { IDC }(\boldsymbol{n}=\mathbf{1 4})}{14(100)}$} & \multicolumn{2}{|c|}{ AMS $(n=34)$} & \multicolumn{2}{|c|}{ Dual-Role $(n=20)$} & \multicolumn{2}{|c|}{ Total $(n=68)$} \\
\hline & & 32 & $(94)$ & 19 & (95) & 65 & $(96)$ \\
\hline IDC pharmacist(s) on service & $13 / 14 \quad(93)$ & $13 / 32$ & (41) & $18 / 19$ & (95) & $44 / 65$ & $(68)$ \\
\hline Infectious diseases physician & $14 / 14(100)$ & $31 / 32$ & (97) & $19 / 19$ & $(100)$ & $64 / 65$ & (98) \\
\hline Medical microbiologist & $7 / 14 \quad(50)$ & $13 / 32$ & $(41)$ & $12 / 19$ & (63) & $32 / 65$ & (49) \\
\hline $\begin{array}{l}\text { Physician (non-infectious } \\
\text { diseases specialist) }\end{array}$ & $0 / 14 \quad(0)$ & $1 / 32$ & (3) & 0/19 & $(0)$ & $1 / 65$ & $(2)$ \\
\hline Infection control practitioner & $4 / 14 \quad(29)$ & $7 / 32$ & $(22)$ & $1 / 19$ & (5) & $12 / 65$ & $(18)$ \\
\hline Nurse & $2 / 14 \quad(14)$ & $3 / 32$ & (9) & $1 / 19$ & (5) & 6/65 & (9) \\
\hline Infectious diseases fellow & $10 / 14 \quad(71)$ & $17 / 32$ & (53) & $13 / 19$ & $(68)$ & $40 / 65$ & (62) \\
\hline Medical resident & $12 / 14$ & $17 / 32$ & (53) & $18 / 19$ & $(95)$ & $47 / 65$ & $(72)$ \\
\hline Medical student & $11 / 14 \quad(79)$ & $13 / 32$ & (41) & $13 / 19$ & (68) & $37 / 65$ & (57) \\
\hline AMS program & $6 \quad(43)$ & 26 & $(76)$ & 18 & $(90)$ & 50 & $(74)$ \\
\hline AMS pharmacist(s) on service & $6 / 6(100)$ & $26 / 26$ & $(100)$ & $18 / 18$ & $(100)$ & $50 / 50$ & (100) \\
\hline Infectious diseases physician & $5 / 6 \quad(83)$ & $24 / 26$ & $(92)$ & $15 / 18$ & (83) & $44 / 50$ & (88) \\
\hline Medical microbiologist & $3 / 6 \quad(50)$ & $19 / 26$ & (73) & $11 / 18$ & $(61)$ & $33 / 50$ & (66) \\
\hline $\begin{array}{l}\text { Physician (e.g., non-infectious } \\
\text { diseases specialist, non-medical } \\
\text { microbiologist) }\end{array}$ & $0 / 6$ & $8 / 26$ & (31) & $1 / 18$ & (6) & $9 / 50$ & (18) \\
\hline $\begin{array}{l}\text { Microbiology laboratory } \\
\text { assistant or technician }\end{array}$ & $0 / 6$ & $3 / 26$ & (12) & $1 / 18$ & (6) & $4 / 50$ & (8) \\
\hline Nurse & $0 / 6$ & $4 / 26$ & (15) & $6 / 18$ & (33) & $10 / 50$ & (20) \\
\hline Infection control professional & $0 / 6$ & $13 / 26$ & (50) & $12 / 18$ & (67) & $25 / 50$ & (50) \\
\hline Hospital epidemiologist & $2 / 6 \quad(33)$ & $2 / 26$ & (8) & $2 / 18$ & (11) & $6 / 50$ & (12) \\
\hline Information systems analyst & $1 / 6 \quad(17)$ & $5 / 26$ & (19) & $7 / 18$ & (39) & $13 / 50$ & (26) \\
\hline Project manager & $1 / 6 \quad(17)$ & $2 / 26$ & (8) & $5 / 18$ & (28) & $8 / 50$ & (16) \\
\hline Hospital administrator & $2 / 6 \quad(33)$ & $10 / 26$ & (38) & $6 / 18$ & (33) & $18 / 50$ & $(36)$ \\
\hline
\end{tabular}

AMS = antimicrobial stewardship, IDC = infectious diseases consultant

Institutional characteristics and features of the IDC services and AMS programs are described in Table 2 and Table 3, respectively. Eight (57\%) of the 14 IDC pharmacists, 19 (56\%) of the 34 AMS pharmacists, and 10 (50\%) of the 20 dual-role pharmacists reported working in an institution with more than 500 beds. Respondents were predominantly employed by institutions serving adults, as indicated by 13 (93\%) of the 14 IDC pharmacists, $28(82 \%)$ of the 34 AMS pharmacists, and 18 (90\%) of the 20 dual-role pharmacists. Overall, 65 (96\%) of the 68 respondents reported the presence of an IDC service at their institutions, and $50(74 \%)$ reported the presence of a funded AMS program. Of the 65 institutions with an IDC service, $44(68 \%)$ had an IDC pharmacist on the team, and all $50(100 \%)$ of the 50 institutions with an AMS program had an AMS pharmacist on the team.

Pharmacists' practice characteristics related to clinical, educational, administrative, and research roles are reported in Table 4. Of note, 12 (86\%) of the 14 IDC pharmacists, 13 (38\%) of the 34 AMS pharmacists, and $9(45 \%)$ of the 20 dual-role pharmacists reported having direct communication with patients. Participation in patient care rounds was indicated by $12(86 \%)$ of the 14 IDC pharmacists, 13 (38\%) of the 34 AMS pharmacists, and 14 (70\%) of the 20 dual-role pharmacists. None of the IDC pharmacists but 12 (35\%) of the 34 AMS pharmacists and $2(10 \%)$ of the 20 dual-role pharmacists specified that their services did not have patient care rounds. Performing antimicrobial interventions was described by all of the IDC and dual-role pharmacists and by $30(88 \%)$ of the 34 AMS pharmacists. Interventions included de-escalation of therapy, dose optimization, and parenteral-to-oral conversion. Educating patients was identified by $10(71 \%)$ of the 14 IDC pharmacists, 7 (21\%) of the 34 AMS pharmacists, and 7 (35\%) of the 20 dual-role pharmacists.

The majority of pharmacists surveyed reported teaching activities. Serving as a preceptor for pharmacy learners on experiential rotations was described by all 14 IDC pharmacists, by $29(85 \%)$ of the 34 AMS pharmacists, and by 19 (95\%) of the 20 dual-role pharmacists.

Administrative responsibilities varied, with AMS program committee membership indicated by $8(57 \%)$ of the 14 IDC pharmacists, 32 (94\%) of the 34 AMS pharmacists, and 19 (95\%) of the 20 dual-role pharmacists. Preprinted order development was reported by 8 (57\%) of the 14 IDC pharmacists, 29 (85\%) of the 34 AMS pharmacists, and 13 (65\%) of the 20 dual-role pharmacists. Antibiogram development was described by 4 (29\%) of the 14 IDC pharmacists, 25 (74\%) of the 34 AMS pharmacists, and $12(60 \%)$ of the 20 dual-role pharmacists.

Ten (71\%) of the 14 IDC pharmacists, 21 (62\%) of the 34 AMS pharmacists, and 14 (70\%) of the 20 dual-role pharmacists reported conducting research intended for publication. The 
This single copy is for your personal, non-commercial use only.

For permission to reprint multiple copies or to order presentation-ready copies for distribution, contact CHHP at publications@cshp.ca

\section{Table 4. Pharmacists' Practice Characteristics}

\begin{tabular}{|c|c|c|c|c|}
\hline \multirow[b]{2}{*}{ Characteristic of Practice } & \multicolumn{4}{|c|}{ Pharmacist Group; No. (\%) of Respondents } \\
\hline & $\operatorname{IDC}(n=14)$ & AMS $(n=34)$ & Dual-Role $(n=20)$ & Total $(n=68)$ \\
\hline \multicolumn{5}{|l|}{ Clinical } \\
\hline $\begin{array}{l}\text { Direct communication with } \\
\text { (speaking to) patients }\end{array}$ & $12(86)$ & $13(38)$ & $9(45)$ & $44(65)$ \\
\hline $\begin{array}{l}\text { Involvement of patients in } \\
\text { decision-making }\end{array}$ & 11 (79) & $6(18)$ & $9(45)$ & $26(38)$ \\
\hline $\begin{array}{l}\text { Participation in patient } \\
\text { care rounds }\end{array}$ & $12(86)$ & $13(38)$ & $14(70)$ & $39(57)$ \\
\hline Antimicrobial interventions* & $14(100)$ & $30(88)$ & $20(100)$ & $64(94)$ \\
\hline Streamlining or de-escalationt & $13(93)$ & $29(85)$ & $20(100)$ & $62(91)$ \\
\hline Dose optimizationt & $13(93)$ & $28(82)$ & $20(100)$ & $61(90)$ \\
\hline Parenteral-to-oral conversiont & $13(93)$ & $26(76)$ & $19(95)$ & $58(85)$ \\
\hline Discharge planning & $10(71)$ & $11(32)$ & $14(70)$ & $58(85)$ \\
\hline Seamless care activities & 11 (79) & $17(50)$ & $17 \quad(85)$ & $45(66)$ \\
\hline Monitoring of drug therapył & $13(93)$ & $25(74)$ & $20(100)$ & $64(94)$ \\
\hline Patient education & $10(71)$ & $7(21)$ & $7 \quad(35)$ & $24(35)$ \\
\hline \multicolumn{5}{|l|}{ Teaching } \\
\hline Experiential rotation preceptor & $14(100)$ & $29(85)$ & $19(95)$ & $62(91)$ \\
\hline Didactic education provider & $11(79)$ & $22(65)$ & $17 \quad(85)$ & $50(74)$ \\
\hline \multicolumn{5}{|l|}{ Administrative } \\
\hline $\begin{array}{l}\text { Member of AMS program } \\
\text { committee }\end{array}$ & $8 \quad(57)$ & $32(94)$ & 19 (95) & $59(87)$ \\
\hline PPO development† & $8 \quad(57)$ & $29(85)$ & $13(65)$ & $50(74)$ \\
\hline Antibiogram development & 4 (29) & $25(74)$ & $12(60)$ & $41(60)$ \\
\hline $\begin{array}{l}\text { NFDR and restricted } \\
\text { antimicrobial approval† }\end{array}$ & $9(64)$ & $22(65)$ & $13(65)$ & $44(65)$ \\
\hline $\begin{array}{l}\text { Antimicrobial therapeutic } \\
\text { interchange development }\end{array}$ & $8 \quad(57)$ & $21(62)$ & $11 \quad(55)$ & $40(59)$ \\
\hline $\begin{array}{l}\text { Clinical practice guideline/ } \\
\text { clinical pathway development† }\end{array}$ & $10(71)$ & $24(71)$ & $18(90)$ & $52(76)$ \\
\hline $\begin{array}{l}\text { Mentoring/management } \\
\text { of pharmacists }\end{array}$ & 11 (79) & $18(53)$ & 11 (55) & $40(59)$ \\
\hline \multicolumn{5}{|l|}{ Research } \\
\hline $\begin{array}{l}\text { Conduct research intended } \\
\text { for publication }\end{array}$ & $10(71)$ & $21(62)$ & $14(70)$ & $45(66)$ \\
\hline $\begin{array}{l}\text { Perform drug-use evaluation } \\
\text { (audit and feedback)t }\end{array}$ & 4 (29) & $28(82)$ & $12(60)$ & $44(65)$ \\
\hline Compile antimicrobial metrics & $6(43)$ & $32(94)$ & $16(80)$ & $54(79)$ \\
\hline \multicolumn{5}{|c|}{$\begin{array}{l}\text { AMS = antimicrobial stewardship, IDC = infectious diseases consultant, NFDR = nonformulary drug request, } \\
\text { PPO = preprinted order. } \\
\text { *Specific antimicrobial interventions are listed under question } 24 \text { in Appendix } 1 \\
\text { (available at www.cjhp-online.ca/index.php/cjhp/issue/view/124/showToc). } \\
\text { †Suggested interventions for AMS programs as outlined in Accreditation Canada's Required Organizational Practice } \\
\text { for AMS. } \\
\text { FSpecific forms of monitoring are listed under question } 25 \text { in Appendix } 1 .\end{array}$} \\
\hline
\end{tabular}

number who reported performing drug-use evaluations (e.g., a chart review to assess use of a particular antimicrobial, followed by provision of feedback to prescribers) was more varied: 4 (29\%) of the 14 IDC pharmacists, 28 (82\%) of the 34 AMS pharmacists, and $12(60 \%)$ of the 20 dual-role pharmacists. Compilation of antimicrobial metrics was also variable: $6(43 \%)$ of the 14 IDC pharmacists, 32 (94\%) of the 34 AMS pharmacists, and $16(80 \%)$ of the 20 dual-role pharmacists.

\section{DISCUSSION}

The findings of this survey provide insight into the key roles and responsibilities of IDC, AMS, and dual-role pharmacists in
Canada. Greater proportions of IDC pharmacists than AMS pharmacists reported speaking to patients, participating in patient care rounds, involving patients in decision-making, and providing patient education. In contrast, development of antibiograms and preprinted orders, collection of antimicrobial metrics, and antimicrobial drug-use evaluations were performed by greater proportions of AMS pharmacists. As expected, dual-role pharmacists performed a combination of the duties reported by the IDC and AMS pharmacists. In the authors' experiences with 3 Canadian health authorities, IDC pharmacists participate in rounds and intervene with their teams to provide direct patient care, whereas AMS pharmacists tend to review patients in terms of targeted 
antimicrobials or interventions, making recommendations informed by chart reviews and/or discussions with the medical teams and prescribers. In institutions with both IDC and AMS pharmacists, there are opportunities for each group to learn from the other, to enhance the skills practised by the other subspecialty.

Pharmacists play an integral role in the multidisciplinary IDC services and AMS programs in the majority of institutions represented by the survey respondents. This involvement supports the important function of pharmacists in the context of infectious diseases. In general, IDC pharmacists represent a minority of specialized pharmacists practising in an infectious diseases-related setting, likely because the number of AMS pharmacists has increased substantially over the past few years (personal observations). This shift may be the result of the Accreditation Canada ROP for AMS acting as an incentive to create new funding for AMS pharmacist positions; however, there is no similar accreditation-related incentive for institutions to assign funds for IDC pharmacist positions. Despite this potential constraint, half of the respondents reported that they worked, at least in part, as an IDC pharmacist. The large proportion of respondents identifying as dual-role pharmacists may reflect a hybridization of roles related to direct patient care pharmacy services and AMS program-related duties in Canada at the time of this survey (in 2015). This study represents the situation at one point in time; the roles and practices of pharmacists may change over time, depending on the site of practice and future changes in Accreditation Canada standards.

It was not surprising that the majority of pharmacists identified as AMS pharmacists, in either a single or dual role, given the Accreditation Canada requirement for every hospital to have a formal AMS program with a pharmacist as a core member. ${ }^{6}$ All 3 groups of pharmacists were performing interventions recommended by the AMS program ROP, such as audit and feedback, management of formulary-targeted antimicrobials with approved indications, creation of guidelines and clinical pathways, development of antimicrobial order forms, de-escalation of therapy, dose optimization, and parenteral-to-oral conversion. ${ }^{6}$ Many of the AMS pharmacists and the dual-role IDC and AMS pharmacists reported performing administrative duties, such as serving as a member of an AMS committee, adjudicating nonformulary drug requests, and performing drug-use evaluations, all of which are tasks aligned with the ROP.

An interesting finding of this study was the frequency with which pharmacists self-identified as dual-role IDC and AMS pharmacists. There may be several reasons for this outcome, including interest and expertise in both infectious diseases and AMS, existing IDC pharmacists taking on additional AMS responsibilities for institutional accreditation purposes, lack of funding for separate IDC and AMS positions, or clinical priorities as determined by pharmacy department resources. Dual-role IDC and AMS pharmacists reported fewer of the unique activities seen among those who practised within a single subspecialty, a result that highlights the importance of specialization in the IDC and AMS positions.

Many survey respondents (54\%) had additional training in infectious diseases or AMS, and the majority had advanced clinical training. These findings suggest that pharmacists taking on these roles are highly qualified to provide antimicrobial interventions and are motivated to pursue further education. Despite the relatively high level of additional IDC or AMS training, it remains important to promote the need for additional education for the other pharmacists in these roles. Both Accreditation Canada ${ }^{6}$ and the AMS program development guidelines of the Infectious Diseases Society of America and the Society for Healthcare Epidemiology of $\mathrm{America}^{3}$ recommend including a pharmacist with infectious diseases training in AMS programs.

A previously published review examined the role of a pharmacist on a multidisciplinary antimicrobial team. ${ }^{7}$ The pharmacist's responsibilities included providing one-on-one education for prescribers (analogous to audit and feedback), running therapeutic interchange programs, providing education to other healthcare providers, developing guidelines, and enforcing antimicrobial restriction policies. The findings of this survey confirm that pharmacists in Canada are performing these activities, among numerous others, as members of their interdisciplinary IDC or AMS teams.

This survey had some limitations. The true response rate could not be clearly established, because the total number of IDC and AMS pharmacists in tertiary care academic hospitals across Canada was unknown. Although we strove to identify all of the IDC and AMS pharmacists in Canada, there was potential for selection bias. As with all surveys, nonresponse bias must also be considered. However, given the high completed-questionnaire response rate (77\%), it is likely that our results are representative of the roles of IDC and AMS pharmacists across Canada in tertiary care academic hospitals. This study did not include pharmacists working in the Yukon, Northwest Territories, Nunavut, or Prince Edward Island, because no tertiary care academic centres were identified in those regions at the time of recruitment. Half of the eligible participants identified were from Ontario, which may have biased the survey results toward IDC and AMS pharmacy practices in that province. Inclusion was restricted to pharmacists practising at tertiary care academic hospitals, so the results may not be generalizable to IDC and AMS pharmacists practising in community or rural settings. A recent survey of AMS programs in Ontario highlighted disparities in program maturity and designated resources among hospitals. ${ }^{14}$ Smaller community hospitals were the least likely to report the establishment of an AMS program before 2013 and the least likely to report availability of dedicated resources. Additionally, this survey represents a snapshot of the self-described roles of IDC and AMS pharmacists in 2015. The responsibilities of pharmacists are 
dynamic; as such, they may have changed since the survey was administered and may continue to evolve as AMS becomes a standard of practice at all institutions in the future.

Despite these limitations, the results of this study may be used to aid hospital and pharmacy management in further refining the job descriptions of IDC and AMS pharmacists, and informing the optimal model of pharmacy support for AMS. This information, in addition to the larger body of literature now available and Accreditation Canada's AMS recommendations, may facilitate policy creation and decisions to fund IDC and AMS pharmacists in Canada. Other health care professionals and pharmacists in IDC or AMS positions can also use these survey findings to improve collaboration and minimize redundancy in their duties.

It may be beneficial to repeat this survey in the future to assess whether the functions of IDC and AMS pharmacists change as AMS programs become better established within institutions. As AMS expands to new practice sites, including community hospitals, residential care, and primary care, it will be interesting to see how our data for tertiary care academic hospitals compare with data from these new settings.

\section{CONCLUSION}

In Canada, it appears that most IDC and AMS pharmacists are practising in an AMS role. IDC pharmacists reported performing different clinical activities, including interacting directly with patients, attending rounds, involving patients in decision-making, and providing patient education, as compared with AMS pharmacists. IDC pharmacists, AMS pharmacists, and those identifying as dual-role IDC and AMS pharmacists identified similar educational responsibilities. AMS pharmacists had more administrative and research roles, including development of antibiograms and preprinted orders, collection of antimicrobial metrics, and antimicrobial drug-use evaluations. Dual-role IDC and AMS pharmacists described fewer of the unique activities that were reported by those practising within a single subspecialty. The results of this survey may assist hospital pharmacy leaders to create policies, define responsibilities, and develop resources for IDC and AMS pharmacists.

\section{References}

1. Hand K. Antibiotic pharmacists in the ascendancy. J Antimicrob Chemother. 2007;60 Suppl 1:i73-6.

2. Knox K, Lawson W, Dean B, Holmes A. Multidisciplinary antimicrobial management and the role of the infectious diseases pharmacist-a UK perspective. J Hosp Infect. 2003;53(2):85-90.

3. Dellit TH, Owens RC, McGowan JE Jr, Gerding DN, Weinstein RA, Burke JP, et al. Infectious Diseases Society of America and the Society for Healthcare Epidemiology of America guidelines for developing an institutional program to enhance antimicrobial stewardship. Clin Infect Dis. 2007;44(2):159-77.

4. Scheckler WE, Bennett JV. Antibiotic usage in seven community hospitals. JAMA. 1970;213(2):264-7.

5. McGowan JE Jr, Finland M. Usage of antibiotics in a general hospital: effect of requiring justification. J Infect Dis. 1974;130(2):165-8.
6. Required organizational practices handbook 2017. Ottawa (ON): Accreditation Canada; 2017 [cited 2017 Nov 21]. Available from: www.gov.pe.ca/ photos/ original/src_rophandbook.pdf

7. Tonna AP, Stewart D, West B, Gould I, McCaig D. Antimicrobial optimisation in secondary care: the pharmacist as part of a multidisciplinary antimicrobial programme—a literature review. Int J Antimicrob Agents. 2008; 31(6):511-7.

8. Bartlett JM, Siola PL. Implementation and first-year results of an antimicrobial stewardship program at a community hospital. AmJ Health Syst Pharm. 2014;71(11):943-9.

9. Gauthier TP, Worley M, Laboy V, Hernandez L, Unger NR, Sherman EM, et al. Clinical infectious diseases pharmacists in the United States: a problem of both supply and demand. Clin Infect Dis. 2015;60(5):826-7.

10. Gorman SK, Slavik RS. Should traditional antimicrobial stewardship (AMS) models incorporating clinical pharmacists with full-time AMS responsibilities be replaced by models in which pharmacists simply participate in AMS activities as part of their routine ward or team-based pharmaceutical care? The "pro" side. Can J Hosp Pharm. 2016;69(1):45-7.

11. About our members - members. Ottawa $(\mathrm{ON})$ : Association of Canadian Academic Healthcare Organizations; 2014 [cited 2015 May 2]. Available from: www.healthcarecan.ca/who-we-are/membership/

12. Three missions, one future. Optimizing the performance of Canada's academic health sciences centres. Ottawa (ON): Academic Health Sciences CentresNational Task Force; 2010 [cited 2017 Nov 21]. Available from: www. healthcarecan.ca/wp-content/themes/camyno/assets/document/Reports/ 2010/External/EN/ThreeMissions_EN.pdf

13. LeBlanc JM, Seoane-Vazquez EC, Arbo TC, Dasta JF. International critical care hospital pharmacist activities. Intensive Care Med. 2008;34(3):538-42.

14. Leung V. Ontario Antimicrobial Stewardship Program (ASP) landscape survey. Toronto (ON): Public Health Ontario; 2016 [cited 2017 Jul 13]. Available from: https://www.publichealthontario.ca/en/eRepository/ASP_ Presentation_Ontario_Landscape_Survey.pdf

Jessica E Beach, BSC(Pharm), ACPR, PharmD, was, at the time of this study, a Pharmacy Resident with Interior Health Authority, British Columbia. She is now with the Pharmacy Department, Royal Inland Hospital, Kamloops, British Columbia.

Tasha D Ramsey, BSc(Pharm), ACPR, PharmD, is with the Pharmacy Department, Nova Scotia Health Authority, and the College of Pharmacy, Faculty of Health, Dalhousie University, Halifax, Nova Scotia.

Sean K Gorman, BSC(Pharm), ACPR, PharmD, is with the Pharmacy Department, Kelowna General Hospital, Kelowna, British Columbia, and the Faculty of Pharmaceutical Sciences, The University of British Columbia, Vancouver, British Columbia.

Tim T Y Lau, BSC(Pharm), PharmD, ACPR, FCSHP, is with Pharmaceutical Sciences, Vancouver General Hospital, and the Faculty of Pharmaceutical Sciences, The University of British Columbia, Vancouver, British Columbia.

Competing interests: None declared.

\section{Address correspondence to:}

Dr Tasha Ramsey

Pharmacy Department

Nova Scotia Health Authority

1796 Summer Street

Halifax NS B3H 3A7

e-mail: tramseypublications@gmail.com

Funding: None received.

Acknowledgements: The authors wish to acknowledge Piera Calissi, BSC(Pharm), PharmD, FCSHP, for thoughtful review of the study protocol and questionnaire. 